\title{
НЕШТАТНЫЕ СИТУАЦИИ В КОСМИЧЕСКОЙ ТЕХНИКЕ И ПРИНЦИПЫ ИХ ПАРИРОВАНИЯ
}

\section{EMERGENCY SITUATIONS IN SPACE TECHNOLOGY AND THE PRINCIPLES OF THEIR PARRY}

S. Solovyov

Summary. The article presents the concept and classification of emergency situations used in the theory of space flight control. The causes of emergency situations, signs of their manifestation and consequences of their impact on space technology during orbital flight are determined. The resulting information about actions for detecting and determining emergency situations in the process of spacecraft flight control is provided. The approach implemented by the on-Board control system of a modern spacecraft in terms of detecting failures, isolating failed equipment, and restoring functionality is briefly presented. The principles of responding to abnormal situations and temporary plan of action at the same time.

Keywords: spacecraft, emergency situation, state analysis, flight control, parry.

\section{Введение}

$\mathbf{y}$ правление полетом любого космического аппарата (КА) обязательно включает в качестве неотьемлемого элемента осуществление того или иного вида контроля, предполагающего наличие обратной связи по контролируемым переменным. Результат контроля достигается за счет осуществления анализа параметров состояния контролируемого КА. Обобщенное понятие «Состояние КА» включает в себя совокупность процессов, режимов работы составных частей КА, параметров орбитального движения и движения КА вокруг его центра масс, определяющее возможность реализации запланированной программы полета.

В конечном итоге, после проведения всех последовательных действий при проведении контроля, как правило, оператором службы управления формируется заключение (обобщения) о состоянии КА и результаты выполнения запланированной программы полета. Очевидно, что существует как минимум два варианта заключения.

Первое - соответствует нормальному состоянию КА, т.е. все значения телеметрических параметров находятся в области допустимых значениях, определенных в экс-

\author{
Соловьев Сергей Владимирович \\ К.т.н., Ведущий конструктор, ПАО РКК «Энергия» \\ С.П. Королёва \\ sergey.soloviev@scsc.ru
}

Аннотация. В статье представлено понятие и классификация нештатных ситуаций применяемое в теории управления космическими полетами. Определены причины возникновения нештатных ситуаций, признаки из проявления и последствия их воздействия на космическую технику в процессе орбитального полета. Приведены результирующие сведения 06 действиях по обнаружению и определению нештатных ситуаций в процессе управления полетом космических аппаратов. Кратко представлен подход реализуемый бортовым комплексом управления современного космического аппарата в части обнаружений отказов, изоляции отказавшего оборудования и восстановления функциональных возможностей. Сформулированы принципы парирования нештатных ситуаций и временная циклограмма действий при этом.

Ключевые слова: космический аппарат, нештатная ситуация, анализ состояния, управление полетом, парирование.

плуатационной документации, конфигурация составных частей КА соответствует запланированной или неизменной относительно предыдущей, а также все запланированные операции и режимы работы составных частей выполнены или выполняются в соответствии с программой полета. Второе заключение является диаметрально противоположным, а именно не нормальным, то есть не выполняется хоть одно их перечисленных условий. Данная ситуация является как минимум ненормальной или нештатной. Подобное заключение приводит к дополнительным действиям в процессе управления полетом КА направленным на локализацию, идентификацию и принятию неотложных мер по парированию или устранению последствий всеми имеющими способами и средствами как на борту КА, так и дополнительными возможностями которые имеет наземный комплекс управления (НКУ).

\section{К^ассификашия нештатных ситуаший}

В общем случае, в космической технике термин «нештатная ситуация» (НШС) определяется как совокупность условий или обстоятельств, обусловленную действием возмущающих факторов, отличающихся от предусмотренных проектами, нормами и регламентами и ведущих к возникновению опасных состояний, угрозу выполнения программы полета или безопасности экипажа КА. 


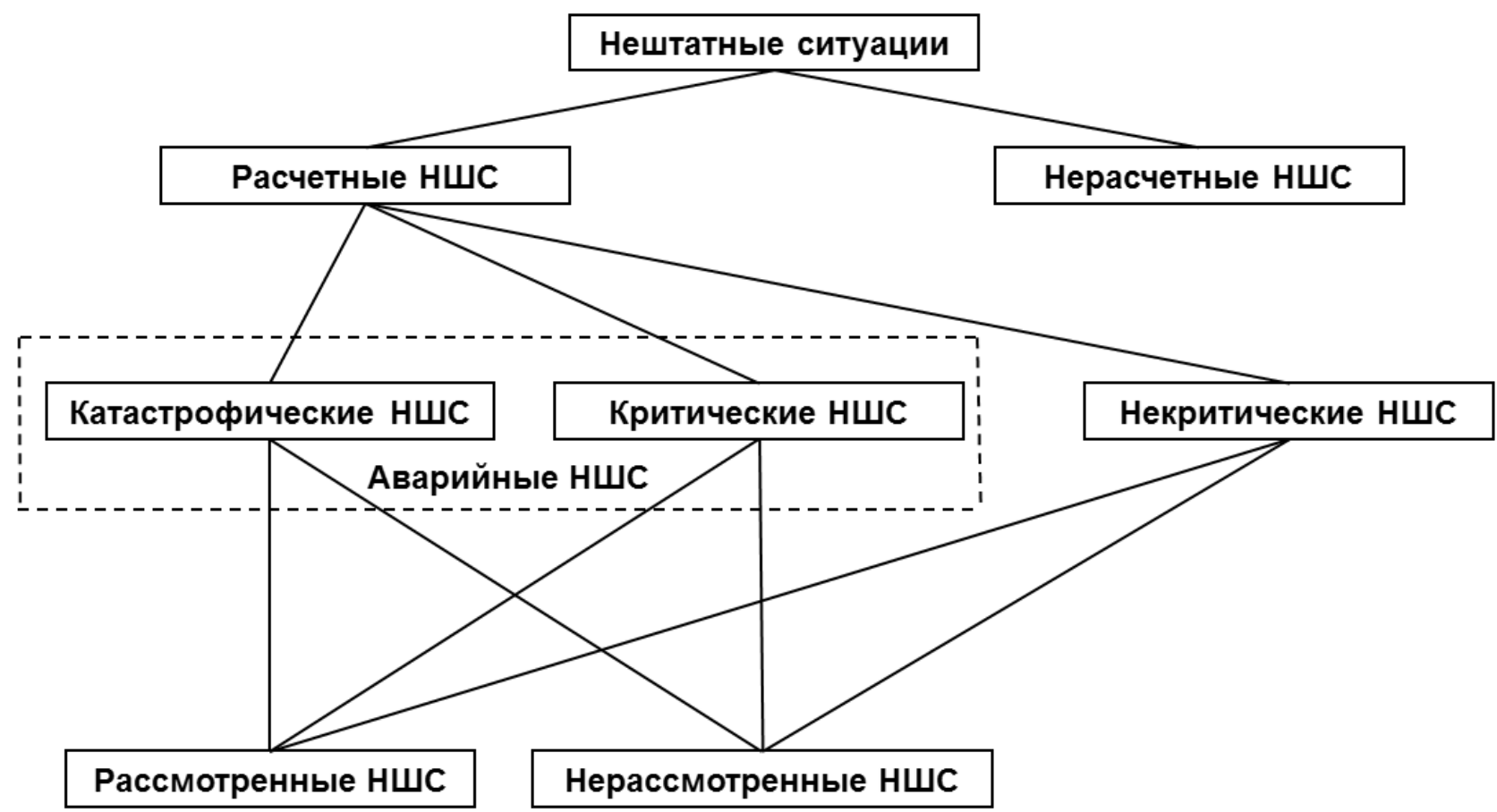

Рис. 1. Классификация НШС в космической технике.

НШС классифицируют в первую очередь по возможности определения, рассмотрения и описания на этапе проектирования КА, а именно:

- расчетная, выход из которой предусмотрен и описан в документации;

- не расчетная, выход из которой невозможен или осуществляется с низкой вероятностью.

Поскольку расчетные НШС описываются на этапе создания КА, то конструктивно КА создается при условии парирования этих НШС. На этом этапе разрабатываются как аппаратные, так и логические способы, позволяющие преодолеть НШС. Важным моментом является и то что первичной целью становиться обеспечение выполнение программы полета при условии обеспечении безопасности экипажа КА и КА в целом.

С этой целью описание каждой конкретной расчетной НШС содержит следующую информацию:

- форма проявления данной НШС;

- отображение данной НШС языком ТМП и параметров, наблюдаемых экипажем КА;

- возможные причины возникновения данной НШС;

- вероятная динамика развития данной НШС;

- расчетные значения временных параметров данной НШС, располагаемое время;

- Методика оперативного определения располагаемого времени на останов развития НШС;

- программа действий по ликвидации данной НШС;
- программа действий в случае, если ликвидация НШС не может быть завершена до наступления её критической фазы (программа «спасательной операции»);

- ресурсы, необходимые для выхода из НШС;

- рекомендации по уточнению плана дальнейшего полёта, связанных с возникновением данной НШС.

Расчетные НШС в зависимости от тяжести последствий, к которым они могут привести, если не будут своевременно ликвидированы, можно подразделить три вида:

- катастрофическими, т.е. сложившиеся в результате неустранимых НШС и приводящие к неспособности КА выполнять дальнейшую программу полета, в том числе и утрата возможности управления полётом KA;

- критические, т.е. которые могут привести к потере функций КА или снижения ее ниже определенной величины что приводит к невозможности выполнения программы полета КА в полном объеме;

- некритические, т.е. не приводящие к критическим и катастрофическим последствиям для КА и/или экипажа КА, а также не приводящая к изменению программ полета.

Катастрофические и критические НШС также объединяются в категорию, именуемую аварийными НШС. 
Причины, признаки и послеАствия нештатных ситуаший

Опираясь на анализ накопленного опыта эксплуатации КА различного назначения, можно констатировать, что в основе возникновения НШС лежат следующие основные первопричины, в том числе:

- неисправность в составных частях, приборах, агрегатах или в элементах конструкции КА;

- ошибка экипажа КА;

- внешние воздействующие факторы космического пространства на КА и его оборудование;

- ошибка или нарушение правил эксплуатации КА, включая некорректные управляющие воздействия на КА со стороны наземного персонала управления;

- нарушение информационного обмена между КА и НKУ;

- неисправности в технических средствах НКУ;

- заболевание или травма проводящая к частичной потере работоспособности членов экипажа КА.

Необходимо отметить, несмотря на указанные причины, которые имели место в практике эксплуатации космической техники, подавляющее большинство НШС связаны с неисправностями в радиоэлектронных приборах КА. Кроме того, КА включает большое число различных радиоэлектронных приборов, а некоторые современные КА, полностью состоят из подобных приборов, а число отдельных электрорадиоизделий превышает сотню тысяч.

Современные КА создаются, как правило, используя базовый проектный принцип, состоящий в обеспечение стойкости КА к единичному отказу или НШС в отдельно взятом приборе КА. Этот принцип предполагает, что бортовой комплекс управления (БКУ) автоматически, без участия наземных средств управления и персонала управления способен выявлять, изолировать и парировать сбои в работе программного обеспечения бортовых вычислительных средств и приборов КА. Реализуется данный принцип на базе самостоятельной технологии обнаружения, изоляции и восстановления за счет возможностей бортового программного обеспечения БКУ. Конструктивно КА на всех этапах полета обеспечивается необходимыми алгоритмами и аппаратными средствами для обнаружения отказа, изоляции отказавшего оборудования и восстановления работоспособности за счет включения в работу резервных элементов в автономном режиме при любом отказе с целью обеспечения выживания КА и минимизации последствий аварии и потребления ресурсов КА (топлива, энергии из аккумуляторных батарей и т.п). В случае обнаружения отказа средствами БКУ выполняется реконфигурация оборудования КА, используются резервные режимы управления или осу- ществляется перевод КА в безопасный режим на время автономного функционирования КА. Безопасный режим должен предотвращать дальнейшее ухудшение состояния КА и минимизировать энергопотребление КА и обеспечить гарантированную генерацию электрической энергии. Безопасный режим должен позволить КА выживать без какого-либо контакта с НКУ в течение, по крайней мере, периода автономности. На этапе выведения КА в составе ракеты-носителя, данная технология обнаружение отказа и алгоритм парирования отказов выполняется только для единичных отказов жизненно важных функций КА (например, терморегулирование, электроснабжение). После отделения КА от ракеты-носителя механизмы обнаружения, изоляции и восстановления отказавшего оборудования автоматически активизируются в полном объеме. После выведения пилотируемых КА первыми проверяются составные части, обеспечивающие возможность возвращения и посадки экипажа на Землю, а для автоматических КА те составные части, которые обеспечивают его выживание. Вся информация о сбоях и отказах на борту КА передается на НКУ с максимальным приоритетом передачи.

Основными признаками возникновения НШС является:

- выход значения какого-либо ТМП состояния КА за допустимые пределы;

- аварийное сообщение от БКУ КА сформированное на основе алгоритмов анализа функционирования как собственно БКУ так контролируемых систем КА;

- изменение конфигурации составных частей КА, выражающийся в переходе на другой комплект оборудования, непредусмотренный программой работы с КА;

- изменение режима работы составных частей КА, отличный от запланированной программы работы с KA;

- нарушение информационного обмена КА - НКУ.

Конкретный ТМП вышедший за пределы, признак или сообщение от БКУ определяет и частично локализует определенный набор рассмотренных НШС, которым оно может соответствовать.

В результате возникновения той или иной НШС, а также при недостаточности или неэффективности мер по ее парированию, могут возникнуть следующие последствия:

- полная утрата способности КА выполнять целевую задачу;

- утрата каких-либо функций, снижение или повышенная скорость деградации технических характеристик, производительности или пропускной способности КА; 


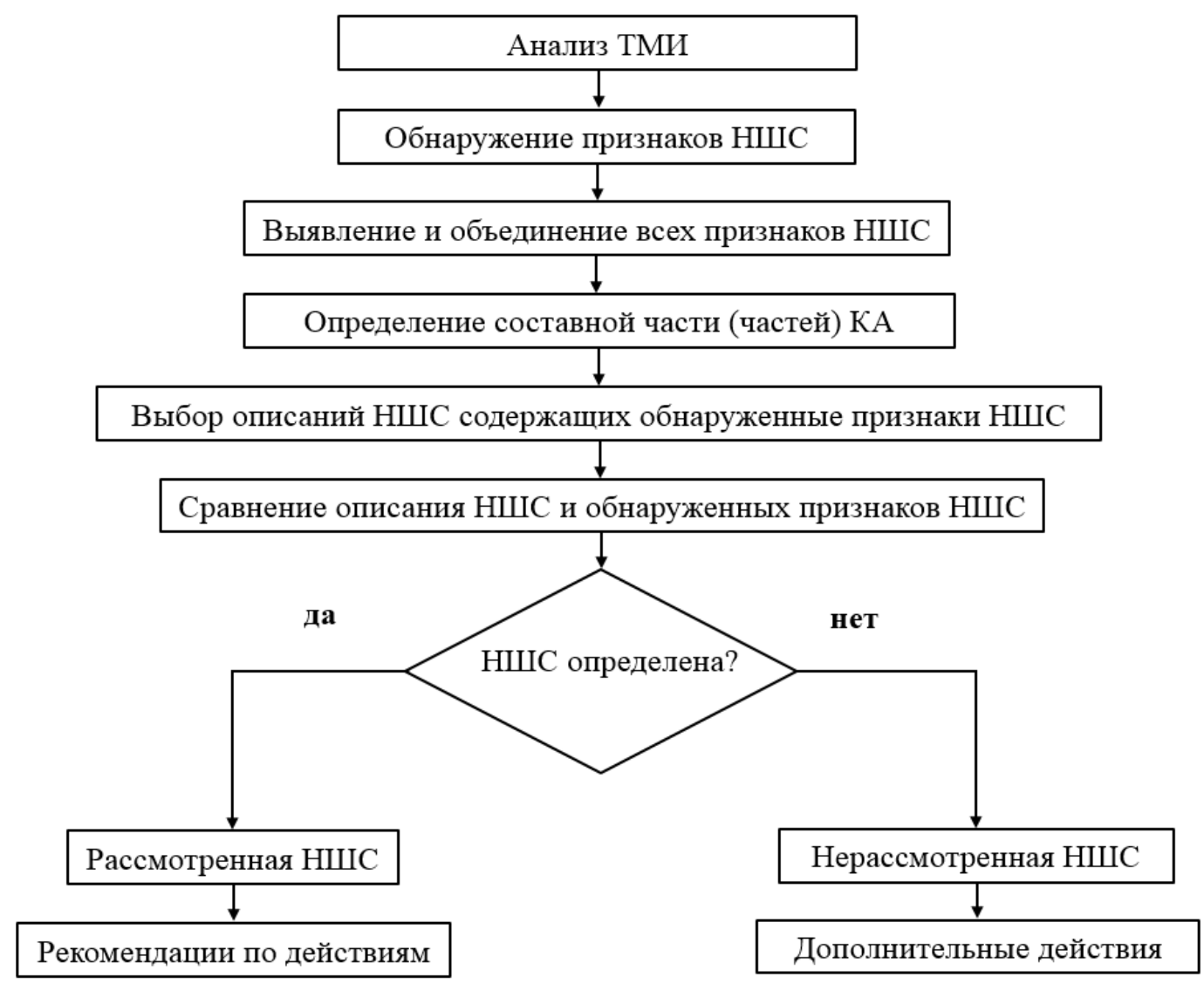

Рис. 2. Методика обнаружения и определения НШС

- невозможность выполнения отдельных полётных операций;

- прерывание выполняемой операции или исполняемого режима;

- невозможность поддержания требуемых параметров орбитального движения КА или его ориентации;

- нарушение условий эксплуатации другого бортового оборудования КА;

- перерасход или ускоренное расходование ресурсов КА;

- снижение уровня безопасности, работоспособности экипажа пилотируемого КА;

- ущерб для здоровья экипажа пилотируемого КА;

- катастрофа, влекущая за собой гибель экипажа, гибель КА.

\section{$\triangle$ ействия по обнаружению \\ и опреАелению нештатных ситуаций}

Чтобы при обнаружении какой-либо признака возникновения НШС определить конкретную возникшую НШС, из числа рассмотренных НШС осуществляются следующие действия. Все фактические признаки возникновения НШС относятся к той составной части КА которые они характеризуют. Для этой составной части или группы составных частей рассматривается все вероятные НШСвер в описание которых внесены обнаруженные признаки НШС. Совпадение описания какой-либо из НШС, входящих в множество НШСвер, позволяет предположить или однозначно установить, как рассмотренную НШС. Предложенная методика обнаружения НШС алгоритмическим образом представлена на рисунке 2.

Анализ НШС осуществляется для различных уровней структуры КА (отдельный агрегат, блок, прибор, составная часть КА). Для этого используются возможности различных алгоритмов управления функционированием и полетом КА: от конкретных циклограмм, формализующих порядок функционирования отдельных агрегатов и составных частей KA, до алгоритмов верхнего уровня управления - алгоритмов программы полета КА.

Перечень расчетный НШС формируется и вноситься в эксплуатационную документацию на стадии разработки КА. Данный перечень пополняется и уточняется на всех этапах создания КА, в том числе и при проведении летных испытаний КА и эксплуатации его по назначению. При этом осуществляется определение влияния каждой из рассмотренных НШС на возможности реали- 
зации программы полета. Исследуются и отрабатываются на наземных средствах программы действий по ликвидации рассмотренных НШС и их последствий, которые при положительном исходе вносятся в эксплуатационную документацию по управлению КА в полете.

В основу этих НШС положены отказы в оборудовании KА, аналитически определяемые в работе составных частей КА до полета, или отказы, возникшие при наземных испытаниях оборудования КА, а также НШС зафиксированные на предыдущих полетах КА или оборудования КА. В число расчетных НШС включают все логически моделируемые и предполагаемые.

Описание каждой конкретной расчетной НШС содержит следующую информацию:

- форма проявления данной НШС;

- отображение данной НШС с помощью значение ТМП;

- возможные причины возникновения данной НШC;

- вероятная динамика развития данной НШС;

- расчетные значения временных параметров данной НШС;

- Методика оперативного определения располагаемого времени на останов развития НШС;

- программа действий по ликвидации данной НШС;

- программа действий в случае, если ликвидация НШС не может быть завершена до наступления её критической фазы;

- ресурсы, необходимые для выхода из НШС;

- рекомендации по уточнению плана дальнейшего полёта, связанных с возникновением данной НШС.

Как упоминалось выше, современный подход к проектированию КА предполагает, что рассмотренные НШС и единичные отказы в составных частях КА контролируются, выявляются, локализуются и парируются посредством БКУ КА с выдачей аварийных сообщений на НКУ и экипажу пилотируемого КА. Поскольку БКУ постоянно работает на борту КА, то и данная функция реализуется непрерывно в течение всего орбитального полета.

Экипаж пилотируемых КА вследствие своей занятости служебными и целевыми операциями обычно осуществляет контроль только ограниченного числа наиболее существенных ТМП с приемлемой периодичностью. Поэтому основная роль в этом случае отводиться автоматизированным средствам БКУ и НКУ.

Наибольшую сложность с точки зрения их анализа, представляют нерассмотренные НШС. Сюда также относятся и скрытые НШС, т.е. те которые не имеют проявления через определенные заранее значения ТМП. Наи- более опасный случай произошел с ТПК «СОЮЗ ТМ-5» 07.09.88 г. когда тормозной импульс не был отработан полностью, траектория спуска не была сформирована, а циклограмма разделения была запушена. Таким образом сложились предпосылки для катастрофической НШС, которые были предотвращены оперативными действиями специалистов.

В настоящее время каких-либо автоматизированных средств для выявления и анализа нерасчетных ситуаций не применяется. При возникновении нерассмотренной НШС во время полета КА в целях анализа специалисты управления используют методологический аппарат действий, основанной на многолетнем опыте предыдущих космических полетов. Действенным способом является «замораживание» ситуации или прерывание идущего режима или полетной операции, для того чтобы иметь достаточное время на выяснение достоверной причины возникновения данной НШС. Последовательность действий включает следующие шаги:

- используя имеющиеся данные ТМИ осуществляется оценка НШС на безопасность КА и работоспособность составных частей КА;

- определяется способность КА к выполнению элементом программы полета;

- осуществляется предварительная оценка располагаемого времени на анализ ситуации и разработку мер по устранению опасности по переходу НШС в критическую фазу;

- формируются вероятностные версии о причинах, вызвавших НШС;

- осуществляется анализ версий, начиная с наиболее вероятной или параллельно если вероятность неопределенна, как логическим образом, так и с привлечением средств моделирования;

- реализуются все возможные дополнительные методы анализа ТМИ для углубленного исследования ситуации;

- осуществляется сравнение логических выводов и результатов моделирование с поведением и КА и его составных частей и величиной ТМП и при взаимном соответствие, версия считается верной, а причина возникновения нерасчетной НШС - определенной.

В настоящее время действенных инструментов автоматического анализа нерасчетных НШС на практике не применяется, поэтому в таких случаях в основном все зависит от знаний, опыта и интуиции специалистов по управлению полетом. Большое значение также придается обеспечению возможности оперативного подключения к работам специалистов разработчиков КА и его составных частей и задействование необходимой инфраструктуры для проверки и отработки версий на наземных моделирующих средствах. 


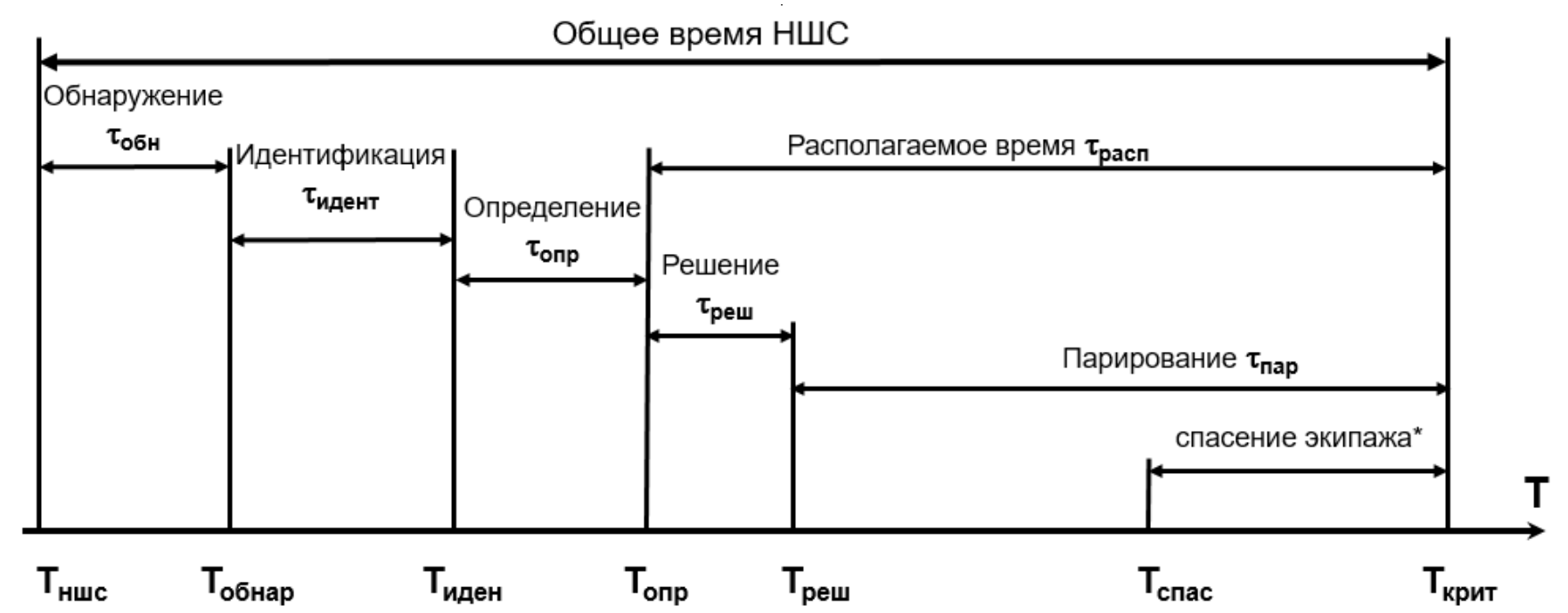

Рис. 3 Циклограмма действий при парировании НШС

\section{Принципы парирования нештатных ситуаший}

Под термином «ликвидация НШС», или «парирование НШС» понимают последовательность действий, направленных на достижение следующих целей:

- прекращение развития или распространения НШС, и недопущения наступления критической фазы по причине данной НШС;

- локализация, определение и устранение причины, породившей данную НШС;

- определение и исключение негативных последствий, вследствие произошедшей НШС и снижение вероятности её повторения на последующих этапах полета КА.

Критическая фаза развития НШС определяется моментом времени перехода КА в состояние, безусловно приводящее к негативным последствиям, указанным выше, включая прерывание выполнения полетной операции, потеря функциональных возможностей КА, снижение производительности или пропускной способности полезной нагрузки КА или возникновение необратимых нарушений состояния КА. Временной интервал между временем обнаружения НШС и временем достижения критической фазы развития НШС определим, как параметр «располагаемое время».

Парирование из НШС реализуется либо автоматически по логике БКУ КА, либо по действиям от НКУ. При парировании НШС силами НКУ дополнительно может накладываться временное ограничение, связанное с возможностями по обмену информации между КА и НКУ, а для межпланетных перелетов и длительность прохождения радиосигнала между КА и НКУ. Для пило- тируемых КА, экипажем посредством ручных органов управления также участвует в парировании НШС.

Анализ НШС и их отбор для рассмотрения производятся по следующим критериям:

- влияние на выполнение программы полета КА и реализации целевой задачи КА;

- влияние на работоспособность КА и его составных частей;

- необходимость ремонтных работ, в том числе выполняемых экипажем.

В практике эксплуатации космической техники сложился устоявшийся порядок действий при анализе НШС всех типов, укрупненный алгоритм которого представлен на рисунке 3, а именно:

- обнаружение или выявление НШС в процессе контроля состояния КА и установление времени её возникновения Тншс;

- локализация и идентификация возникшей НШС;

- параллельно осуществляется поиск причины возникновения НШС;

- определение момента наступления критической фазы НШС Ткрит;

- оценка величины располагаемого времени трасп на парирование НШС;

- выработка программы действий по парированию НШС в соответствии с эксплуатационной документации или по результатам анализа;

- реализация программы действий по парированию НШС.

Для пилотируемых КА и ОК дополнительно обеспечивается решения задачи обеспечения безопасности при невозможности парирования НШС в требуемые сроки 
и реализации программы по спасению экипажа. При этом принимается

Принципиальными методическими приемами парирования НШС, реализуемыми как бортовыми алгоритмами БКУ КА, так и действия специалистов службы управления полетом, при обнаружении НШС, нарушающей реализации программы полета КА следующие:

- переход с отказавшего оборудования на резервное;

- переход на резервный режим работы оборудования или составной части КА;

- прерывание полетной операции и повтор ее в дальнейшем либо исключение её из программы полёта;

- отключение или изоляция оборудования и недопущения распространения НШС на другое оборудование или составную часть КА;

- совокупность вышеперечисленных действий, в зависимости от конкретных обстоятельств и требований эксплуатационной документации.

Парирования НШС направленно на полное восстановление состояния КА и реализации целей полета или программы полета в полном объеме. Достигается в том числе частично, с потерей резервирования, утратой или ухудше- ния некоторых функций или производительности КА. В зависимости от этого, дальнейшая программа полета либо соответствует ранее запланированной, либо корректируется пот существующее техническое состояние КА.

\section{Выво $\triangle \mathrm{b}$}

При реализации процесса управления космическим полетом результатом контроля является определение состояния КА, которое бывает, как минимум в виде двух прямо противоположных заключений: «нормальное состояние КА» когда все значения ТМП находятся в допустимых, планируемых и ожидаемых значениях, «нештатное состояние КА» когда хотя-бы одно значение ТМП вышло за допустимые значения или не выполнена запланированная операция. Последствия НШС могут быть различными, от не влияющих на полет КА, до катастрофических. Обнаружение и идентификация НШС является самостоятельной задачей контроля, при этом первоочередным является определение располагаемого времени до перехода НШС в критическую фазу. Технология действий при парировании НШС состоит в выполнении всех необходимых действий до наступления катастрофических последствий и максимально возможном обеспечении продолжении программы полета для достижения выполнения всех целей полета.

\section{ЛИТЕРАТУРА}

1. Кравец В. Г., Любинский В. Е. Основы управления космическими полётами. М.: Машиностроение, 1983. 256 с.

2. Наземный комплекс управления дальними космическими аппаратами. Перспективы развития/Под ред. Ю. М. Урличича. М.: Радиотехника, 2012.216 с.

3. Современная телеметрия в теории и на практике /А.В. Назаров, Г. И. Козырев, И. В. Шитов и др:- СПб.; Наука и техника, 2007. - 672с.

4. Любинский В. Е. Концепция создания системы управления полетом пилотируемого межпланетного корабля. Полет, 2004, №7, с. 28 -34.

5. Микрин Е. А. Бортовые комплексы управления космических аппаратов. Учебное издание. Издательство МГТУ им. Н. Э. Баумана. 2014 г. — 246 стр. 